\title{
Sexism, English and Yoruba
}

\author{
Yisa Kehinde Yusuf (Botswana)
}

\section{Abstract: \\ Sexism, English and Yoruba}

This paper surveys the incidence of sexism in the structure and use of English, and compares it with corresponding aspects of Yoruba. Subsequently, it examines the areas in which, due to the co-existence of the two languages in southwestern Nigeria, the languages influence one another with regard to sexism.

The paper shows that while Yoruba is not sexist in some respects in which English is, English imposes sexism on the language. It shows also areas in which sexism existing independently in both languages reinforce one another. Finally, it shows how sexism in Standard English seems to have been eliminated in the formation of Nigerian Pidgin English which derives from the contact between English and Yoruba.

\section{Introduction}

"It is men who have made the world which women must inhabit, and if women are to begin to make their own world, it is necessary that they understand some of the ways in which such creation is accomplished. That means exploring the relationship of language and reality."

Dale Spender, Man Made Language.

In multilingual and multicultural environments like Nigeria, a unique opportunity is provided for studying, in its varied intralingual and interlingual forms, aspects of the structure and use of language that demonstrate the male control over the world. For example, by virtue of the fact that Yoruba and English co-exist in southwestern Nigeria as a first language and a second language respectively, the following questions may be asked:

(i) In what ways are English and Yoruba different in structure and use with regard to sexism?

(ii) In what ways are they similar?

(iii) Do they jointly consolidate sexism?

(iv) Do the languages impose sexism on each other?

(v) Do they in any way eliminate sexism from one another? 
The aim of this paper is to provide answers to these questions by examining, one after the other, the structure and use of English and Yoruba and, subsequently, by examining evidence of inter-influence between the languages.

\section{$2 \quad$ Sexism in English}

Sexism in language in general comes in three major forms: language ignores women, it defines them as less significant than men, and it outrightly deprecates the female (Henley 1987, Gomard 1995, West et al 1997 and Romaine 1999). The English Language ignores (or obscures) women by allowing masculine terms to be used specifically to refer to males and generically to refer to human beings in general. The most significant manifestation of the sexism is in the use of the generic masculine pronoun he and its variants as in the sentence

Every good citizen should love his country more than himself; he should be ready to die for it if the need arises.

Another version of the use of the generic or 'neutral' masculine is in the use of man (and related compound words like the Blackman and the-man-in-the-street) to cover the female as in

Man is a thinking animal.

Various studies have sought to show the problems that can arise for women from the use of the generic masculine. The first is that cognitive confusion can arise when generic and specific meanings cannot be easily distinguished (Martyna 1980). An interesting example of such confusion which Moulton et al (1978: 1034) give is the sentence

All men are mortal

in which the use of men seems to be clearly generic or 'neutral'. They note however that if it were neutral, it would be possible for the second line of the syllogism of which the sentence forms a part to be

Sophia is a man.

Considering its usual interpretation, Moulton et al note that it would be difficult to take the sentence to mean that Sophia is a member of the human species. Rather, the sentence would be regarded as false or insulting. They further note that the second line of the syllogism is normally or appropriately

Socrates is a man. 
The sex-specific use of man here betrays an equivocation in the use of what is commonly thought to be a generic noun: there is a switch from the generic in the first line of the syllogism to the specific in the second.

The second problem which Martyna (1980) associates with the use of the generic masculine is that the confusion it generates can lead to the exclusion of the female (see also Cameron 1985 and Wolfe et al 1989). Moulton et al (1978: 1035) similarly state, from the result of an experiment involving two hundred and twenty-six male and two hundred and sixty-four female college students, that

even when a context is clearly specified as gender-neutral (e.g. describing a student in a co-educational institution), male terms used "neutrally" induce people to think of males. To the extent that coming more readily to mind confers an advantage, females are disadvantaged when they are part of a population referred to by a parasitic "neutral term".

Bate (1988) illustrates the disadvantageous behavioural and social effects that the use of the generic masculine can have with a personal experience. In her last year of doctoral study, a job notice was sent to her department which read "We need three good men... One man should be able to..." Nothing in the advertisement indicated clearly whether female PhDs were eligible for appointment. So, none of the women candidates in the department (including Bate) applied, even when a reviewed job notice arrived a month later with the word men changed to faculty members. Though they did not believe that a major public institution would discriminate openly in the mid-1970s, all the female candidates in the department agreed that the risk was too great. In other words, while there could have existed no doubt whether men were included in the generic masculine references, women had the problem of ascertaining whether they were (see also Spender 1985, Stanley 1977, Pauwels 1999 and Jones 2000).

In a concise summary of the significance of the generic masculine, Spender (1985: 157) states:

Through the introduction of he/man, males were able to take another step in ensuring that in the thought and reality of our society it is the males who become the foreground while females become the blurred and often indecipherable background. He/man makes males linguistically visible, and females linguistically invisible. It promotes male imagery in everyday life at the expense of female imagery so that it seems reasonable to assume the world is male until proven otherwise. It reinforces the belief of the dominant group that they, males, are the universal, the central, important category so that even those who are not members of the dominant group learn to accept this reality.

As a solution to the problems that the generic masculine can create, a number of proposals have been made. One of these is that the generic masculine be replaced with he or she, him or 
her, and the like, which expressly indicate that women are included in the antecedent of the pronouns (see e.g. Dubois and Crouch 1987). This strategy can be illustrated with the following sentence:

Every good citizen should love his or her country more than him or herself; he or she should be ready to die for it if the need arises.

Alternatively, it has been proposed that the gender-neutral third person pronoun they and its forms be used with a singular meaning (see e.g. Nilsen 1979 and Cheshire 1985). The proposal makes it possible to say

Every good citizen should love their country more than themselves; they should be ready to die for it if the need arises.

Some have even suggested the use of the 'generic feminine' pronoun she and its variants (see e.g. Cameron 1985). On the basis of the suggestion, one would be able to say

Every good citizen should love her country more than herself; she should be ready to die for it if the need arises.

New gender-neutral pronouns have in addition been created as replacements for the generic masculine pronoun (see e.g. Miller and Swift 1976, Nilsen 1977a and Key 1996). In one of such creations, $e$ is used to mean he or she, and ir stands for him or her and his or her (Eade 1979: 231). This proposal would make the following sentence acceptable:

Every good citizen should love ir country more than irself; $e$ should be ready to die for it if the need arises.

The most popular solution to the problems that can derive from the use of the generic man is its replacement with human being, person, or other neutral terms (see e.g. Graham 1975, Stanley 1977 and Maggio 1987). The replacement would transform the syllogism mentioned above as follows:

All human beings are mortal.

Socrates is a human being.

Therefore, Socrates is mortal.

This transformation allows us to replace the masculine Socrates with the feminine Sophia, and still have a valid syllogism as is shown below:

All human beings are mortal.

Sophia is a human being.

Therefore, Sophia is mortal. 
Using person when reference is made to a human being whose sex is not known or not relevant would reduce women's feeling of exclusion. For example, women would have less problems with the statement 'We need a highly competent person for the job' than they would with 'We need a highly competent man for the job'. The same is true of such word pairs as chairperson: chairman, the Black person: the Blackman, the-person-in-the-street: the-man-inthe-street and so on. Since it may be necessary in some situations to indicate that the people being referred to are not children, the combinations woman or man and woman and man have been seen as useful replacements for the generic masculine noun. The same is true for the term adult.

Though the above proposals of alternatives to the generic masculine follow sound linguistic principles, they have been vehemently criticised and/or resisted (see e.g. Ehrlich and King 1998 and Goddard and Patterson 2000). He or her and woman and man, for example, have been regarded as clumsy and the singular they has been called ungrammatical. A specific quite recent example is in the following note in the usage guide to First Steps with Ladybird $A B C$ (Clark 2000) in the Ladybird children book series: "To avoid the clumsy 'he/she', the child is referred to throughout [this book] as 'he'" (copyright page). Proponents of linguistic equity have also been regarded as "hysterical and hypersensitive" (see Gomard 1995) and feminist efforts at non-sexist change in English have been described by, for example, Heintz (2000: 2-3), as an undesirable tampering with "the world's most elegant and expressive language" by "ignorant and insecure women". Thorne and Henley (1975), Stanley (1977) and Meyers (1989), among others, have impressively defended non-sexist language against these and other criticisms. As such, equitable gender-related language change has continued to occur (see e.g. Pauwels 1991, 1999, Talbot 1998 and Romaine 1999).

Besides ignoring and obscuring women, as have been shown above, the English Language defines women as less significant than men. In fact, Nilsen (1977b) notes that most nouns in the language are considered to be basically male, so that an extra word or affix is needed when the referent has to be specified as female (see also Gershuny 1977). This sexist attitude is reflected in the prince: princess, major: majorette, lawyer: woman lawyer, and truck driver: lady truck driver pairs. Certainly, it is not difficult to see how the attachment of the feminine suffixes '-ess' and '-ette' to prince and major respectively to form feminine words indicates the significance of the female only as an appendage to the male (see Goddard and Patterson 2000).

The suggestion that women are an appendage to the male is related to the male-bias in word combinations in which separate words refer to the female and the male. In he or she, man and woman, Adam and Eve, brothers and sisters, and many other such combinations, the male come first. They take precedence over the female, since they have been classified as the 'worthier' sex (see Cheshire 1985, Henley 1987 and Romaine 1999). The few exceptions to this pattern (e.g. ladies and gentlemen and, especially, bride and bridegroom) fall within the lexicon of what is stereotypically regarded as the female domain - marriage and sexual relations (Nilsen 1977c). 
But even within this so-called female domain, the experience of the male seems to be what is primarily named or defined and not that of the female. For instance, the word foreplay describes an act that precedes or facilitates penetration by the male and their attempt to achieve orgasm. According to Spender (1985) and Cameron (1985), for example, what is described as foreplay may not constitute a preliminary act for women, but may, in fact, be the end of the act. Since what is done during foreplay includes the stimulation of the clitoris, it may constitute, for the woman, "the most satisfying part of heterosexual lovemaking" (Cameron 1985: 81).

It is believed also that the word penetration betrays a male slant in the lexicon of sex and sexuality, because from a female point of view, what is done during heterosexual lovemaking would be more appropriately described as enclosure (see e.g. Spender 1985: 178 and Cameron 1985: 81). Like penetration, the words fuck, poke, and screw make the sexual act into something that is done to women (Cameron 1985).

Another term which reflects the male-centredness of the English Language is illegitimacy. Spender (1985: 181) notes that "it is only the male who need the apparatus of the state to legitimate their role", since the question of not having a 'legitimate' parent cannot arise for a woman who has just borne a child." Interestingly, the 1978 edition of the Longman Dictionary of Contemporary English defines illegitimate as "....born to a mother who is not married."

Nilsen (1977c: 140) states, in relation to the concept of illegitimacy, that "the feeling is very strong that before a person is really part of our society, he or she must demonstrate an affiliation with a father, by a surname." Surnaming and its counterpart, marital re-naming, therefore form very significant aspects of the cultures of English-speaking people that have drawn the attention of feminists immensely. Coryell (1971: 59) observes that "in studying patriarchy, I learned that women and children came to bear the husband's and father's name because he owned them." In the same direction, Alia (1984: 35) states that "marital re-naming is a form of linguistic domination, with the new name less symbolic of change than ex change (a transfer of ownership from father to husband)" (see also Bosmajian 1972, Hamblen 1979, Poynton 1989, Key 1996 and Romaine 1999).

Surnaming and marital re-naming have links with the use of Miss and Mrs. According to Thorne and Henley (1975: 29), "to call people Mrs or Miss is to help maintain a definition of women which relegates them primarily to family roles" (see also Bate 1980, Bosmajian 1977 and Talbot 1998). But even within the family which has been classified as their domain, women are symbolised as insignificant. It has therefore not been possible to pass down women's names by giving their children names like Jennifer, Jr. (Nilsen 1977c: 139). In the opinion of Spender (1985: 24), "one...direct result of this practice of only taking cognizance of the male name has been to facilitate the development of history as the story of the male line." The desire to perpetuate the male line has given rise to the widespread preference for male children, since female children obscure or obliterate father's identities on marrying. 
Women have tried to find a number of solutions to the problem of sexist naming. They have, among others, retained their maiden names on marrying; they have adopted the title $M s$ to de-emphasise the undue perception of marital status as a definitive feature of a woman's identity and personality; they have adopted compound or hyphenated names formed from maiden names and husbands' names; they have taken their mothers' first names as last names; and they have taken some other names that came purely from their imagination, as is the case with the creation of the new last name Kramarae as a means of expressing dissatisfaction with the already existing Kramer, and the creation of Alia from the Hebrew word aliyah which means "to go up" (see e.g. Alia 1984:35, Kramarae and Jenkins 1987, Spender 1985, Ashley 1989, Penfield 1987, Kramarae 1981 and Smith 1985).

In connection with the various attempts to name more fairly, Ashley (1989: 68-69) says,

If it were not for custom, each person, male or female, whatever their marital status, ought best to go through life with one name of their own, producing a better sense of identity, independence, and an easier time with credit, banks, and all record-keeping generally.

One wonders however whether the whole business of feminism is not predicated upon the necessity to eradicate all inequitable, demeaning, or sexist customs. In other words, in addition to having only personal names and avoiding the use of Miss and Mrs, word formation processes that symbolise women as appendages to men must be shunned; word orders that consolidate the pre-eminence of men must be reversed; and women's experiences must be more fairly named and appropriately characterised (see e.g. Spender 1985 and van den Bergh 1987).

The third thing the English Language does to women is that it deprecates them. Referring to its general form, Gershuny (1977: 143) says,

First, we have to deal with rigid verbal stereotypes of masculinity and femininity that are used not only to describe people and language, but also to judge and polarize the phenomenal world into superior/inferior and positive/negative. The inferior and negative poles tend to characterize the female stereotype, the superior and positive, the male.

With a similar orientation, Spender (1985: 23) states:

The semantic rule which has been responsible for the manifestation of sexism in the language can be simply stated: there are two fundamental categories, male and minus male. To be linked with male is to be linked to a range of meanings which are positive and good: to be linked to minus male is to be linked to the absence of these qualities, that is, to be decidedly negative and usually sexually debased... 
In the English Language, when a woman has sexual intercourse for the first time, she is not described as giving away her virginity; rather, it is taken away from her: she is disvirgined or deflowered (Nilsen 1977c: 137). These words suggest that in engaging in sex, the woman is dispossessed of some aspect of her sexuality. But even when higher control over her sexuality is demonstrated by a woman as happens when she is a 'prostitute', it does not bring about her elevation. Hundreds of demeaning synonyms (e.g. whore, tart, slattern and harlot) therefore exist for the word prostitute (see Schulz 1975). In order to suggest that prostitution is normally a female activity, when a man engages in it, he is referred to as a male prostitute.

As a further manifestation of what Graham (1975: 61) refers to as being "assigned to a semantic house of ill fame", feminine titles of honour such as queen, governess, madam, mistress, lady and dame have been degraded and have all in one form or the other been associated with prostitution or fornication (see Schulz 1975 and Chimombo 1998). Feminine terms such as old maid, spinster and heroine have also acquired negative connotations, because while the first two seem to be taken to suggest ill-luck in the matter of marriage, heroine is the name of a destructive drug (see Cheshire 1985 and Cameron 1985).

One other example of the deprecation of women which Nilsen (1977b: 32) and Dundes (1976), among others, draw attention to is their comparison to food through such slang or terms of endearment as dish, cookie, tart, cheesecake, sugar and spice, cute tomato, honey and sweetie pie. These slang underscore the 'edibility' of women. Incidentally, in Nigerian Pidgin English, one of the synonyms of fuck is chop ('to eat'). To have sex with a woman is therefore 'to eat her'.

The stereotype that the female are inferior is manifested in the value attached to the names girls are given. Nilsen (1977b: 30) observes that though it is acceptable for a girl to take a boy's name, it is regarded as unacceptable for a boy to take a girl's. Moreover, because of the negative characterisation of the female, when girls have taken names that were once acceptable for males, for example, Evelyn, Carroll, Gayle, Hazel, Lynn, Beverly, Marion, Francis and Shirley, the names have lost prestige by becoming less and less acceptable for males (Nilsen 1977b: 31).

Regarding the implications of deprecating women linguistically, Spender (1985: 23-24) states in the same direction as Schulz (1975), Bate (1988) and Romaine (1999), among others, that

The semantic derogation of women fulfills a dual function: it helps to construct female inferiority and it helps to confirm it... In a society where women are devalued the words which refer to them - not surprisingly - assume negative connotations. But because the options for defining women are confined to negative terms, because their meanings are primarily those of minus male, women continue to be devalued.

As a solution, women have attempted to reclaim the obsolete positive meanings of some terms and have tried to create new positive meanings for others. For example, women have 
referred to themselves as 'hags', 'witches', and 'spinsters' to show that they have control over what they are called and how they are treated (Kramarae and Jenkins 1987: 140; see also Cameron 1985: 80 and Pauwels 1999: 2).

\section{$3 \quad$ Sexism in Yoruba}

Unlike English, Yoruba has no gender-specific pronouns. The question of having a generic one does not as such arise. Oun can mean either 'she' or 'he', re may be 'his' or 'her', and won or awon ('they') could be either singular or plural (Yusuf 1988). The Yoruba pronoun system is therefore non-sexist and represents the kind of ideal for which advocates of the reformation of the English Language have been striving.

Generic masculine nouns of the 'man' kind are also rare in Yoruba. The Yoruba term awon okunrin ('men') can therefore not occupy the subject position in the Yoruba translation of "All men are mortal", if the mortality of women is implied as well. If awon okunrin were to be placed in the subject position, the Yoruba sentence that would be produced is

\section{Gbogbo okunrin ni yoo ku.}

The only English translation that this sentence can have is

All male human beings are mortal.

In order to include the female, the generic man can be replaced in a Yoruba translation only by eniyan ('people' or 'human beings') or by any of its synonyms such as eda. In this case, the Yoruba sentence that would be semantically equivalent to the generic 'All men are mortal' would be

Gbogbo eniyan ni yoo ku.

Noteworthy in this regard is the fact that the Yoruba equivalent of the proverb 'Man proposes, God disposes' is

Riro ni t'eniyan, sise ni t'Olorun.

Here, the word eniyan ('human beings' or 'a human being') rather than okunrin ('man') carries the notion represented by the generic 'man' in the English proverb.

However, some generic masculine or sexist terms exist in Yoruba. Two of them are Baba mi ('My father') and Oko mi ('My husband'). They are used as metaphors to refer generically to and praise a child or younger relative, male or female, who has done some impressive thing. They are used also for instance, to console a sad or crying child or younger relative or to 
express a get-well-quick wish to a sick one. They are in addition used to persuade the child or younger relative to carry out an instruction (see Yusuf 1993). The use of these terms is restricted to the children's mothers or elderly female relatives.

In order to praise, the speaker addresses the child or younger relative in one of the following two sets of ways:

(i) O kare, baba mi or Baba mi, o seun.

('Well done, my father' or 'My father, thank you.')

(ii) O seun, oko mi or Oko mi, o seun.

('Thank you, my husband' or 'My husband, well done.')

To console or express concern for a sick child or a younger relative, the speaker says either of the following:

(i) Pele, baba mi or Baba mi, dakun. ('Sorry, my father' or 'My father, please.')

To persuade the younger person to do or not to do something, the elderly one issues an instruction, and as if it has been carried out, thanks them in one of the following sets of ways:

(i) O kare, baba mi or Baba mi, o seun.

('Well done, my father' or 'My father, thank you.')

(ii) O kare, oko mi or Oko mi, o seun.

('Well done, my husband' or 'My husband, thank you.')

The use of these generic metaphors symbolises an affinity between being a father or husband, on one hand, and endearing behaviour and positive achievement, on the other. It may, like other generic usages of masculine terms, facilitate the belief in the natural superiority of the male (see e.g. Martyna 1980, Hill 1986 and Henley 1987).

Sexist word formation processes that allow, for example, the formation of princess from prince in English do not exist in Yoruba. In the language, both princess and prince are called omo oba ('a ruler's child').

But word-ordering that suggests the secondary status of women can be found in the language as it is in English. For example, in l'okunrin l'obinrin ('male and female') and t'oko t'aya ('husband and wife'), okunrin ('male') and oko ('husband') come before obinrin ('female') and aya ('wife') respectively. In finding out what the sex of a newborn baby is, the question $A k o$ $n$ 'babo? ('Male or female') is asked. This ordering of the masculine and the feminine in the question is, however, reversed when one seeks to find out whether the result of some undertaking is positive or negative. In that case, the question becomes Abo n'bako? ('Female or male?'). Here, abo ('female') is the metaphor of the positive and ako ('male') is the metaphor of the negative. In fact, the English compliment 'Happy New Year' is translated into 
Yoruba as Odun a y'abo ('May the Year be female'). To wish people that their new year be male is to curse them.

What the preceding seems to confirm is the suggestion that, in word-ordering, the worthier gender comes first. It may therefore be said that since the male comes first in Ako n'babo? ('Male or female?') and the female comes first in Abo n'bako? ('Female or male?'), the male is regarded as more desirable in one context and the female in the other. However, this suggestion may not be entirely correct, because while the male (ako) comes before the female (abo) in Pele l'ako o l'abo ('"Sorry" has masculine and feminine versions'), it is the one that comes in second position that is worthier or more desirable. While the uttering of the feminine "Sorry" is the expression of a genuine apology, the masculine is the expression of an insincere or cynical one. It is interesting to note also that the expression mu u l'ako ('to handle it in a male way') implies the handling of an issue tactlessly.

In the lexicon of sex, male-bias does not seem to be prevalent. The Yoruba expression that is semantically equivalent to the English word foreplay is fi owo para won l'ara (literally, 'rub hand against one another's body'). The male-bias evident in the word penetration does not exist in Yoruba, because its Yoruba equivalent d'obo ('fuck vagina') indicates what a man does to a woman, but has a complement d'oko ('fuck penis') which describes what the woman does to the man during sexual intercourse.

However, there is a male slant in the terms for a promiscuous person. While a promiscuous woman is described as odoko ('a fucker of a husband [i.e., an adulterous woman]'), a promiscuous man is described as yan-ale-yan-ale or oyanle ('one who takes a concubine') rather than *odoyawo ('a fucker of a wife'). It is important to note that yan-ale-yan-ale can refer to both the male and the female, because the word ale refers to both a woman's male sex partner and a man's female one. However, not having an easily ascertainable father is the only factor that would qualify a child to be called omo ale ('a concubine's child' or 'an illegitimate child').

The most deprecating feature of the Yoruba language is in the definition of women by the position of their vagina and the manner in which they urinate. A woman is referred to as atehinto ('one who urinates from behind'). The term is used by a man to express his disgust and sense of humiliation when a woman excels him in some endeavour. In addition, it is used when a man wishes to indicate that it is unimaginable for a woman to excel him, or that he would not tolerate some behaviour or action from a woman.

In normal Yoruba culture, children are not given surnames. Instead, they are given only personal names which may be feminine, masculine, or gender neutral (see Yusuf 1989, 1993). A feminine personal name is Iyabo ('Mother has come back'), and it is given to the first girl to be born to her parents after the death of her female grand-parent. A masculine one is Babatunde ('Father has come back'), and is given to the first boy to be born after the death of his male grand-parent. An example of a gender-neutral Yoruba personal name is Olawumi ('I love prosperity'). 
A Yoruba child carries their personal names throughout their life. In other words, marital re-naming does not take place in traditional Yoruba culture. The question of marking marital status as Miss and Mrs do does not therefore arise. The wife may be described (not labelled) as the wife of $\mathrm{X}$, while the husband may equally be described as the husband of Y (see Yusuf 1989). In other words, Yoruba naming practices, like its pronoun system and word formation principles, are unlike those of English non-sexist.

\section{Sexism-related inter-influence between English and Yourba}

Sexism from English has been imposed upon the structure and use of Yoruba in at least two ways. One instance of this is the borrowing of the sexist English word baby, as a term of endearment for one's adult female lover, into Yoruba. In the language, terms that are connotationally synonymous with baby (e.g. arobo and omo agbo) are used to describe both adult females and males who exhibit what is believed to be a childish or immature trait. They are clearly uncomplimentary terms and so are not used as terms of 'endearment'. However, baby has been borrowed into Yoruba Language, and it helps to express the sexism that arobo and its synonyms cannot express. As such, the word baby now exists in Yoruba with the meaning 'adult female lover'. The popularisation of the word has been especially facilitated by the music of Western-styled or Western-influenced Yoruba artistes (Yusuf 1989).

Another evidence of the imposition of the sexist structure of English on Yoruba is found in the surnaming of the children of Westernised parents and the adoption of husbands' names by Westernised wives (see Yusuf 1989). As has been mentioned above in the section on sexism in Yoruba, in a traditional Yoruba home, a child would be given only personal names which she or he would carry throughout their life, whatever their marital status may be. However, with the imposition of British colonial rule on the country and the acquisition of Western education by the Yoruba, children started to be given surnames and women began to adopt their husbands' names as was the case in the cultures of the colonisers.

Two institutions seem to have facilitated the adoption of these sexist tendencies. They are Western educational and healthcare institutions (see Yusuf 1993). It seems to be the pattern (from my personal experience) that when children are to be registered into pre-primary and primary schools or health clinics, and their parents give the children's personal names, the registering officers insist that fathers' names be included. Similarly, when married women are to be registered at healthcare establishments, their husbands' names are required. With time, it has become necessary or expedient in many cases to give children surnames at birth and for wives to adopt their husbands' names.

With the adoption of the sexist marital renaming practice, it has become necessary also to create new meanings for some existing Yoruba words so that they can clearly indicate marital status. The words aya ('wife') and omidan ('unmarried girl') are significant in this regard. Aya, the antonym of $o k o$ ('husband'), which normally used to be only a descriptive term has now 
come to be used as a label like Mrs. Yoruba names like Adewumi Aya Ajijola (Mrs. Adewumi Ajijola) are as such widespread now in southwestern Nigeria. Omidan ('unmarried girl') which used to be applied descriptively as an antonym of abileko ('one who has a husband's home' [i.e., 'a married woman']) has also become the Yoruba representation of the English Miss. Names like Omidan Bola Adigun (Miss Bola Adigun) can therefore now be found especially in the Yoruba mass-media.

Unlike omidan, apon ('unmarried man') is not used as a marital-status indicating title. One can therefore not find names like*Apon Taiwo Adedayo. In other words, the English double standard of defining women in terms of marital status, while not doing the same to men, has been effectively implanted into the Yoruba Language (Yusuf 1989). Incidentally, the word Arabinrin is comparable to $M s$ in that it does not indicate the marital status of the women whose names it precedes. For example, Arabinrin Adewumi Ajijola simply is Ms Adewumi Ajijola.

The sexist English practice of taking the name of a father or husband and the sexism of the Yoruba generic terms Baba mi ('My father') and Oko mi ('My husband') co-exist in the Westernised Yoruba home and are mutually reinforcing. The co-existence of these sexist practices may be said to be capable of jointly socialising young people to expect the co-occurrence of being a father or husband with endearing behaviour and positive achievement (Yusuf 1993). They may help to reinforce the sexist belief that the male is the superior sex.

The imposition of the sexist structure of English on Yoruba is also found in the translation of non-sexist Yoruba proverbs into sexist English. Yoruba proverb collections in which such translation has been done include J.O. Ajibola's (1947) Owe Yoruba and I.O. Delano's (1979) Owe L'esin Oro: Yoruba Proverbs - Their Meaning and Usage. An example from Ajibola (1947) is entry 4 which is given below with its translation:

\section{Abanije mba ara re je.}

'He who slanders others lowers his own prestige.'

In the translation, the word abanije which is gender-neutral in Yoruba should non-sexistly be interpreted as 'one (or a person) who slanders others', and ara re should non-sexistly be interpreted as 'herself/himself' or 'themselves'. The proverb should therefore non-sexistly have been translated as, for example,

'One who slanders others slanders themselves.'

However, Ajibola's English translation masculinises the gender-neutral words so that abanije becomes 'He who slanders others' and ara re becomes 'his own prestige'. 
In Delano (1979), an example of a sexist English translation of a non-sexist Yoruba proverb is entry 71 which with its translation is as follows:

Gbolohun kan ba oro je, gbolohun kan tun oro se.

'One sentence may spoil a man's case, one sentence may improve a man's case.'

The curious thing about the English translation of this proverb is that there is no direct reference to a human being in the Yoruba proverb. In other words, the sexism in the English translation does not arise from the imposition of a specific gender on a gender-neutral word, but from the interjection of a masculine word into the translation of a proverb that makes no overt reference to a human being. In order to make the two occurrences of the word 'man' in the English translation to be regarded as the imposition of a masculine interpretation on a gender-neutral word, the Yoruba proverb would need to be expanded as follows:

Gbolohun kan ba oro [eniyan] je,

Gbolohun kan tun oro [eniyan] se.

If the Yoruba proverb must retain its original form, its more accurate, non-sexist English translation would be

'One sentence may spoil a case, one sentence may improve a case.'

Braun (1995:25) is thus right when, in studying the translation of gender-neutral Finnish forms and sentences as masculine in English and German, she notes that this tendency "is...not only relevant (and harmful) from a feminist perspective, it is also incorrect from a linguistic point of view".

While sexism in English has been imposed upon non-sexist aspects of Yoruba Language, Yoruba seems to have eliminated sexism from English in a way. This phenomenon is manifested in the pronoun system of Nigerian Pidgin English. Though further research needs to be carried out in order to be able to say with a very high degree of certainty the exact contribution of Yoruba to the pronoun system of the pidgin, it has been observed that (probably with the exception of him represented as im in the pidgin) the generic he and its forms do not exist in Nigerian Pidgin English as they do in Standard English (Yusuf 1993). As in Yoruba, the feminine English she, masculine he, neuter it, and generic he are represented by only one pronoun in the pidgin. The pronoun is $e$ or $i$ and is pronounced $/ \mathrm{i} /$. It is significant to note that $i$ is also a Yoruba gender-neutral pronoun, as is shown in the sentence

Mo ri $i$.

('I saw her, him, or it.')

Mo is 'I', $r i$ is 'saw', and $i$ is 'her, him, or it'. 


\section{Conclusion}

From the foregoing, it is evident that Yoruba is like English sexist in some respects, and is unlike English non-sexist in others. It is also shown that sexism from both languages are in some respects mutually reinforcing. Moreover, there is evidence that sexism in English has been imposed on some otherwise non- sexist aspects of Yoruba Language, and that the contact between the languages may have prevented the transfer of some sexist features of Standard English into Nigerian Pidgin English.

My studies have not yet revealed evidence of the elimination of sexism from Standard English by Yoruba, nor have they yet found evidence of the imposition of sexism on English by the language. All the same, the instances of the inter-influence between the two languages that are shown in this paper indicate that the study of languages in contact constitutes a dimension of the study of sexism that should continue to attract the keen interest of both linguists and feminists.

\section{Refrences}

Ajibola, J. O. (1947): Owe Yoruba. Ibadan.

Alia, Valerie (1984): "Women, Names, and Power". Women and Language VIII. 1/2: 34-36.

Ashley, Leonard R. N. (1989): What's in a Name? Baltimore.

Bate, Barbara (1988): Communication and the Sexes. New York.

Bosmajian, Haig A. (1972): "The Language of Sexism". ETC: A Review of General Semantics 29.3: 305-313.

Bosmajian, Haig (1977): "Sexism in the Language of Legislatures and Courts". In: Nilsen, Alleen Pace et al. (eds.): 77-104.

Braun, Friederike (1995): "Making Men out of People: The MAN Principle in Translating Genderless Forms". Working Papers on Language, Gender and Sexism 5.2: 5-38.

Cameron, Deborah (1985): Feminism and Linguistic Theory. New York.

Cameron, Deborah (ed.) (1998): The Feminist Critique of Language. $2^{\text {nd }}$ Edition. London.

Cheshire, Jenny (1985): "A Question of Masculine Bias". English Today 1: 22-26.

Chimombo, Moira P.F. / Roseberry, Robert L. (1998): The Power of Discourse. London.

Clark, Lesley (2000): First Steps with Ladybird ABC. London.

Coryell, Julie (1971): "What's in a Name?". Women: A Journal of Liberation 2: 59.

Dégh, Linda / Glassie, Henry / Oinas, Felix. (eds.) (1976): Folklore Today: A Festschrift for Richard M. Dorson. Bloomington.

Delano, Isaac O. (1979): Owe L'esin Oro: Yoruba Proverbs - Their Meaning and Usage. Ibadan.

Dubois, Betty L. / Crouch, Isabel (1987): "Linguistic Disruption: He/She, S/he, He or She, He-She". In: Penfield, Joyce (ed.): 28-36.

Dundes, Alan (1976): "The Crowing Hen and the Easter Bunny: Male Chauvinism in American Folklore". In: Dégh, Linda / Glassie, Henry / Oinas, Felix. (eds.): 123-138. 
Eade, Alan. J. (1979): "WORDS AND POLITICS: To Each Their(?) Own". ETC: A Review of General Semantics 36.3: 230-233.

Ehrlich, Susan / Ruth King (1998): "Gender-based Language Reform and the Social Construction of Meaning". In: Cameron, Deborah (ed.): 164-179.

Gershuny, H. Lee (1977): "Sexism in Dictionaries and Tests: Omissions and Commissions". In: Nilsen, Alleen Pace / Bosmajian, Haig / Gershuny, H. Lee / Stanley, Julia P. (eds.): 143-159.

Goddard, Angela / Patterson, Lindsey Meân (2000): Language and Gender. London.

Gomard, Kirsten (1995): "The (Un)equal Treatment of Women in Language: A Comparative Study of Danish, English, and German". Working Papers on Language, Gender and Sexism 5.1: 5-25.

Graham, Alma (1975): "The Making of a Nonsexist Dictionary". In: Thorne, Barrie / Henley, Nancy (eds.): 57-63.

Hamblen, C.H. (1979): "The Married Woman's Name: A Metaphor of Oppression". ETC: A Review of General Semantics 36.3: 248-256.

Heintz, Stephen (2000): "The Tarnishing of English". The Vocabula Review (Online) 2.6: 1-4. Henley, Nancy M. (1987): "The New Species That Seeks a New Language: On Sexism in Language and Language Change". In: Penfield, Joyce (ed.): 3-27.

Hill, Alette Olin (1986): Mother Tongue, and Father Time. Bloomington / Indianapolis.

Jones, Pamela (2000): "Words That Stab Like a Sword". The Vocabula Review (Online) 2.7: 4-10.

Key, Mary Ritchie (1996): Male/Female. With a Comprehensive Bibliography. $2^{\text {nd }}$ Edition. Lanham/ MD. /London.

Kramarae, Cheris (1981): Women and Men Speaking. Rowley / Massachusetts.

Kramarae, Cheris / Jenkins, Mercilee M. (1987): "Women Take Back the Talk". In: Penfield, Joyce (ed.): 137-156.

Lont, Cynthia / Friedley, Sheryl A. (eds.) (1989): Beyond Boundaries: Sex and Gender Diversity in Communication. Fairfax.

Maggio, Rosalie (1987): The Nonsexist Word Finder: A Dictionary of Gender-Free Usage. New York.

Martyna, Wendy (1980): "Beyond the He/Man Approach: The Case for Nonsexist Language". SIGNS: Journal of Women in Culture and Society 5.3: 482-493.

Meyers, Miriam W. (1989): "Adult Writers' Generic Pronoun Choices". In: Lont, Cynthia / Friedley, Sheryl A. (eds.): 63-74.

Miller, Casey / Swift, Kate (1976): Words and Women: New Times. Garden City / New York.

Moulton, Janice / Robinson, George M. / Elias, Cherim (1978): "Sex Bias in Language Use: 'Neutral' Pronouns That Aren't". American Psychologist 33.11: 1032-1036.

Nilsen, Alleen Pace (1977a): "Linguistic Sexism as a Social Issue". In: Nilsen, Alleen Pace et al. (eds.): 1-26.

Nilsen, Alleen Pace (1977b): "Sexism as Shown through the English Vocabulary". In: Nilsen, Alleen Pace et al (eds.): 27-41.

Nilsen, Alleen Pace (1977c): "Sexism in the Language of Marriage". In: Nilsen, Alleen Pace et al. (eds.): 131-140. 
Nilsen, Alleen Pace (1979): "You'll Never Be the Man Your Mother Was, and Other Truisms". ETC: A Review of General Semantics 36: 365-370.

Nilsen, Alleen Pace / Bosmajian, Haig / Gershuny, H. Lee / Stanley, Julia P. (eds.) (1977): Sexism and Language. Urbana / Illinois.

Pauwels, Anne (1991): "Sexism and Language Planning in English-speaking Countries: Some Issues and Problems". Working Papers on Language, Gender and Sexism 1.2: 17-30.

Pauwels, Anne (1999): "Feminist Language Planning: Has It Been Worthwhile?". Linguistik Online 2.1/99: 1-10.

Penfield, Joyce (1987): "Surnaming: The Struggle for Personal Identity". In: Penfield, Joyce (ed.): 117-129.

Penfield, Joyce (ed.) (1987): Women and Language in Transition. Albany / New York.

Poynton, Cate (1989): Language and Gender: Making the Difference. New York.

Romaine, Suzanne (1999): Communicating Gender. London.

Schulz, Muriel R. (1975): "The Semantic Derogation of Women." In: Thorne, Barrie / Henley, Nancy (eds.): 64-75.

Smith, Philip M. (1985): Language, the Sexes and Society. New York.

Spender, Dale (1985): Man Made Language. $2^{\text {nd }}$ Ed. London.

Stanley, Julia P. (1977): "Gender-Marking in American English: Usage and Reference". In: Nilsen, Alleen Pace et al. (eds.): 43-74.

Talbot, Mary M. (1998): Language and Gender. Cambridge.

Thorne, Barrie / Henley, Nancy (1975): "Difference and Dominance: An Overview of Language, Gender, and Society". In: Thorne, Barrie / Henley, Nancy (eds.): 5-42.

Thorne, Barrie / Henley, Nancy (eds.) (1975): Language and Sex: Difference and Dominance. Rowley / Massachusetts.

van den Bergh, Nan (1987): "Renaming: Vehicle for Empowerment". In: Penfield, Joyce (ed.): 130-136.

van Dijk, Teun A. (ed.) (1997): Discourse as Social Interaction. London.

West, Candace / Lazar, Michelle M. / Kramarae, Cheris (1997): "Gender in Discourse". In: van Dijk, Teun A. (ed.): 119-143.

Wolfe, Susan J. / Struckman-Johnson, Cindy / Flanagin, Judy (1989): "Generic 'Man': Distribution, Acquisition and Perception". In: Lont, Cynthia / Friedley, Sheryl A. (eds.): 51-61.

Yusuf, Kehinde (1988): "A Critique of the Linguistic Arguments for the Possibility of Desexing Thought by Degenderising English". Ife Studies in English Language 2.1: 87-92.

Yusuf, Kehinde (1989): "English Imposed Sexism in Yoruba Language: The Case of 'Baby' and 'Aya'". Women and Language XII.2: 27-30.

Yusuf, Yisa (1993): "The Diffusion of the Male-Favored Praising, Consolation, and Persuasion of Children in Yoruba and Sexist Naming in English". Research in Yoruba Language and Literature 4: 101-104 